\title{
My Name Is Sue. How Do You Do! (Names and Identity)
}

\author{
Irina Perianova \\ University of National and World Economy \\ Sofia, Bulgaria \\ E-mail: i.perianova@unwe.bg
}

Received: December 9, 2014 Accepted: December 24, 2014 Published: March 26, 2015

doi:10.5296/iss.v3i1.6758

URL: http://dx.doi.org/10.5296/iss.v3i1.6758

\begin{abstract}
The paper aims to give an overview of the functions of proper names as a complex multi-dimensional phenomenon. While implying certain conceptual characteristics proper names reflect the way people see themselves, or what others might infer about them, and thus shape their attitude. As part of the cultural discourse they serve as determinants of social identity. An important feature of personal names is their potential to be used metaphorically as characterizers and signifiers. Naming conventions depend on culture, generation, status and existing linguistic forms. Avoiding a name as a form of address is culture-based, or expresses attitude and affect. Furthermore, names are an instrument of control, submission and otherisaton. They are also a marker of memory and trust as well as a signifier of status. The disparity of addressing when, for example, one of the speakers uses the first name and the other one the surname, always implies some kind of inequality. The drift of the current changes in naming/addressing in the West is egalitarian and characterized by greater informality and reciprocity.
\end{abstract}

Keywords: proper names, identity, control, power, otherisation, status, social change, memory, affect, sobriquets 


\section{Introduction}

The paper is entitled "My name is Sue. How do you do!" At a certain point the famous lyrics by Johnny Cash continue menacingly: "Now you gonna die." Out of context the link between the greeting and the explicit threat would seem totally incomprehensible. What is the relevance of the name Sue and how does it tie in with the threat? The song The Boy Named Sue describes a boy who had to live with a girl's name which created a lot of problems for him. In the end it turned out that giving the son a girl's name was a means chosen by his father to condition the boy's behaviour and his attitude - the aim was to make the boy 'tough and mean', learn to fight and protect himself from a very early age:

And he said: "Son, this world is rough

And if a man's gonna make it, he's gotta be tough

And I knew I wouldn't be there to help you along.

So I gave ya that name and I said goodbye

I knew you'd have to get tough or die.

And it's the name that helped to make you strong"

In many cases, real and fictional alike, as in this popular song, one's real or perceived identity is a function of the person's name. This assumption clashes with most dictionary definitions reading that "proper names are expressions to designate a person, place or thing and they imply no characteristics beyond use of the name to designate its referent." (OCEL: 727) In this paper I plan to show that proper names and their different linguistic forms are not just tags but have certain semantic, pragmatic and socio-cultural functions. It is my view that a name, say, Sue, is part of a discourse system and while denoting a person called Sue it is a frame interpreted by drawing different implicatures.

\section{Proper Names and Denotation}

While it is true that ... "a proper name is a noun that is the name of a single particular thing or a person" (LDELC, 2005) this definition is only the tip of an iceberg in onomastics. In addition to denoting a single referent, the name Sue denotes a class of people called Sue and all these people have something in common - at least all of them supposed to be female, or face living with an infringement of a naming convention, as in the song above, with dire consequences. If names were a designation of a single particular person we wouldn't find the following dialogue from the film Four Wedding s and a Funeral, with Hugh Grant as Charles, hilarious:

(1) Charles (Hugh Grant): - Hello, my name is Charles

Old man: - Don't be ridiculous, Charles died 20 years ago

Charles: Must have been a different Charles.

Old Man: - Are you telling me I don't know my own brother? 


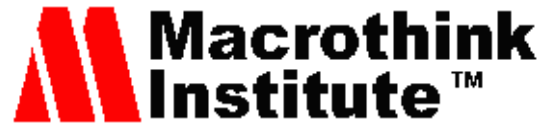

Issues in Social Science

ISSN 2329-521X

2015, Vol. 3, No. 1

Thus, semantically speaking, proper names designate anybody who was, is, or will be called Charles. However, it is not the only relevant characteristic of proper names.

One of the most important features of proper names is that they are an integral part of shared cultural knowledge and may signify something specific for an entire community. The well-known examples are the famous Shakespearean proper names used as common designators of some qualities their original bearer is associated with - Romeo, Juliet, Hamlet, Shylock, etc. This metaphorical characterization is a common function of proper names encoding conceptual information which in the examples above may be shared by community at large. The names reach out to the present with the metaphorical echoes of the past.

In example (2a), out of context the codification would be completely obscure. It involves local (individual) knowledge only and is indicative of a frequently noted ability of proper names to be used metaphorically and stand for certain qualities attributed to the bearer of the name. Alistair is the name of a former boyfriend who symbolizes for the heroine rudeness and hard-nosed selfishness. The interpretation of example (2b), on the other hand, presupposes world knowledge - parallels may be drawn between Cristina Fernandez and Hillary Clinton, the former First Lady and an aspiring Presidential candidate in the USA.

(2) a. Until Leo, she had almost reached a point of seeing herself as wrong and the Alistairs of this world as right. (Rendell, 1997: 209)

b. A Hillary of Argentina? Buenos Aires has its own First Lady on the move

(Newsweek, Dec. 25, 2007)

Significantly, the key to interpreting this function of the proper names is representation by resemblance, a concept developed by Sperber and Wilson (1986) in the context of the relevance theory. I would assume that the number of contexts where proper names represent, generalize and interpret could be infinite.

\section{Names and Social Identity}

Because of their given names people may be identified as members of a certain social and ethnic group or generation. At an ESSE conference in London (September 2006) Kathleen S., a symposium convener, was immediately placed as 'Ostdeutscher' (East German) by a West German academic because of her 'non-Wessie' name, Kathleen, very unusual in the former West Germany for her generation (personal communication - Dr. Hans-Ulrich Mohr).

Anthony Giddens (1991:55) writes: “A person's name ... is a primary element in his biography; practices of social naming, how far names express kin relations, whether or not names are changed at certain stages of life - all these things differ between cultures." Johnny Cash's song about the Boy Named Sue is a graphic generalization of Austin's (1962) speech act theory with its underlying argument that language is used not just to say things but to do things.

Names influence people's lives in many ways: they often determine both the way we communicate and want to be perceived and the way we are perceived. In many cultures names also depend on fashion. Thus, Shirley was popular in the 1930s in English-speaking 
communities because of the child actress Shirley Temple (OCEL: 764). Giles and Nigel are signally middle-class names, Alistair and Ian are traditional Scottish names (Ibid). This attitude to names - as generational and class markers seems to be universal. In Bulgaria, for example, international names, such as Tania and Natalia, were very popular in the 60-ies and 70-ies and many Bulgarian women "elevated" themselves to Tania from the traditional names, such as Stoyanka, and Stanka, which to them sounded rural and common, as opposed to the urban and sophisticated sound of Tania.

The following extract (3) illustrates how names may be evocative of national identity:

(3) My name is Matilda Wilson and I am the Headmistress of the Antipodean Academy of Learning in Singapore" the speaker announced. Before we go any further let me say that though my name is Matilda and I am Australian I do not dance and if I did it would certainly not be the waltz. (Dorney, 2004:23)

The speaker implies the Australian national symbol, Waltzing Matilda, “... a popular old Australian song which many Australians think of as their national song. It tells the story of a 'swagman' (a worker who travels around the country carrying his possessions with him." (LDELC) Generally speaking, a host of common proper names are used as stereotypical and insulting designators of national identity with varying regularity in different countries: Ivan for Russian men and Natasha - for Russian women (especially as sexual objects), Fritz or Hans for Germans, Hasan and Aishe - for Turks, Ab/v/ram- for Jews, Garabed - for Armenians, etc.

\section{Names and Control}

Names are an instrument of control, submission and sometimes of otherisation both for individuals and society at large. According to Jane Rhys (1997) Rochester in Jane Eyre has a way of controlling his wife by giving her the name Bertha which is more appropriate to Victorian English society than her given name Antoinette. This change of names makes Mrs. Rochester lose her voice, origin and as a consequence - her identity. In general, signifying is a very important function of the name and frequently, as in this case, it results in redrawing identity borders. It is also a powerful political instrument. In Bulgaria the compulsory renaming of ethnic Bulgarian Turks during the so-called national revival process in the era of Todor Zhivkov provoked a wave of civil unrest. In late 1970ies and 1980ies ethnic Turks were forced to renounce their Turkish and Arab names and adopt Bulgarian names. In this way Ahmed became Angel, Izet - Ivo, Aishe - Ania. The change of names targeted assimilation but the Turkish names were a marker of people's collective identity and a new enforced identity symbolized by new names could not be adopted because it was viewed as a gross violation of personal space.

A recent case that involves politics and names is related to the conflict between Russia and Ukraine. It exemplifies a political statement - perceiving names as a threat to one's own identity. In September 2014 a Ukrainian politician, Irina Farion, visited a day care centre in her home town of Lviv and urged children with the names Masha and Misha to either change their names, or have their suitcases packed and go and live where other Mashas and Mishas 
live - i.e. Russia. Numerous indignant comments followed in social networks in both Russia and Ukraine as politics caught up with the identity of little children who were otherised due to their Russian names.

A graphic illustration of an individual attitude as it is signified by names is given in the following extract from Sea Voices by Keith Miles. In the story Byron Morris has a beautiful voice which he uses to seduce and control women. In his mind he calls all his mistresses Pats (4 a-d) thus giving them a common identity and rejecting their own voice:

(4) a. Her nod triggered off his golden voice, his special Byronic voice, his dark and manly voice, his patter for this and every Pat. A few minutes of gold and her smile broadened into agreement. A probable Pat. (Miles, 1977: 175)

b. Mutual laughter in the wind. A definitive Pat. (Ibid, 176)

As the story unfolds Byron meets two women in their forties who say they are scientists:

(4) c. Neither of them were exactly up to the Pat standard individually. But together, well, why not? Colleague Pats. Joint possibilities. (Ibid: 178)

d. Both were positives in the Pat sphere. Double Pats. A before and after Pat.A left and right Pat. (Ibid: 180)

Not surprisingly, in the end "the Pats" take their revenge on Byron.

\section{Names, Avoidance and "the Other"}

First names and surnames are used with varying frequency in different linguistic and cultural communities depending on the characteristics of culture and the inherent pragmatics, as well as on the socio-cultural features of a given group - age, gender, status, class. This usage as I have already pointed out above, is not a fixture - it may be governed by fashion or tradition.

The use or avoidance of certain names in different cultures may be related to any type of background knowledge and cultural practice (see also Perianova, 2002). Names of certain relatives or small children are avoided in many cultures - in Africa, Latin America, the Pacific region. Thus, in New Guinea Kara community it is taboo to mention the personal name of an in-law of the opposite sex. A man cannot mention the personal name of his wife's sister, nor a woman mention the name of her husband's brother. There are alternative ways of making reference to an in-law. A brother-in-law may be referred to as Josephine's husband, her husband, the children's father, Aliku (in law). (Aisoli Oraki, 2002) The Yanomamo of Venezuela and Brazil, on the other hand, have a strict taboo on using the personal names of relatives who have died. In addition, courtesy and respect are demonstrated through avoiding the use of the personal names of living relatives. (Chagnon, 1992).

Furthermore, using or avoiding the use of first names, or last names is a sign of intimacy and friendliness or distancing and animosity. In Flann O'Brien's The Third Policeman, the narrator does not have a name. His having no name means that nothing can be stolen; no name means, as it becomes apparent at the end of the book, no life, deconstruction of identity. 
In European cultures, avoiding an address may sometimes be tantamount to a rejection or scorn. See, for instance, the example (5):

(5) Her resentment took the curious form of her ceasing to use my Christian name when she spoke to me. ... Instead of, "Coffee's ready, Elizabeth," she would say, "There's coffee if you want it", or calling upstairs "Are you there?" and waiting until the appropriate voice answered. (Vine, 1988: 117)

A reluctance to use Elizabeth's given name signifies dislike and resentment.

Some names may seem unsuitable because of religious or cultural taboos as illustrated in (6) in English-speaking cultures Jesus is used as an interjection, but not as a personal name:

(6) Marcus roared with laughter, breaking off to call out, "Jesus-Jesus!”

Victoria looked startled, but it appeared that Jesus was the barman's Christian name. Victoria felt again that the East was an odd place. (Christie, 1984:76)

One of the artistic failures while representing the reality of the Other is often an inappropriate naming of characters. As G. Apostolova's analysis (2006) of the use of such allegedly Bulgarian names as Viktor Krum (by Joan Rowling in Harry Potter), and Petar Solinsky (by Julian Barnes in Porcupine) seems to suggest, these pseudo Bulgarian names, impossible in real-life situation, are indicative of the reification of a false reality which Bulgarians cannot identify with because of the differences in the discourse codes. The same applies to the names in Alan Furst's (Note 1) Night Soldiers (1998) with its unlikely and unnatural Bulgarian surnames - Stoianev and Omar, and pseudo-Bulgarian first names - Veiko, Teodor, Helena.

\section{Names as Memory, Oblivion, Trust}

Names are a marker of memory and oblivion and people's identity is revealed or hidden by names. In Eva Hoffman's seminal book Lost in Translation, when the author and her sister lose their Polish names Ewa and Alina and become Eva and Elaine they perceive it as a radical change of identity: 'Our Polish name didn't refer to us; they were as surely us as our eyes or hands. The new appellations, which we ourselves can't yet pronounce, are not us. They are identification tags, disembodied signs pointing to objects that happen to be my sister and myself." (1989:105) Similar to in other similar cases involving emigration to 'a new country of hope', new names symbolized trust in the new destiny and were inextricably bound to the

new identity. For a long time, however, until the new name settled in, the girls' existence was liminal:

(7) Who was I, after all? Eva's ghost, perhaps, a specter that tried not to occupy too much space. (Hoffman, 1989: 114)

The new name was a vehicle to propel Ewa across the border and turn into Eva but "the Cracow Ewa" was more real for a long time, and never forgotten.

Names may become vehicles of big politics but the powers that be should be ready to confront resistance. In Bulgaria, during the renaming process when the decision of the 
Communist party of Bulgaria was enforced by the State Security, new names went against the grain - a change of name had not been a conscious decision of the people concerned but a compulsory regulation used as a means of control and was therefore perceived as institutional rejection of the Turkish ethnic identity. This practice caused protest and led to what was ironically referred to as "mass excursion", or emigration to Turkey. The new "Stoyans" did not want to renounce the memory of countless Hasans, Ahmeds and Aishes in their ancestry and mistrusted the government which enforced this decision. They did not believe that new names would result in a new destiny and they would be accepted as real Stoyans.

As a whole, memory is of great importance in building up and preserving identity. In the words of Eva Hoffmann: "Milan Kundera knows that a person who forgets easily is a Don Juan of experience (Note 2), promiscuous and repetitive, suffering from the unbearable lightness of being." (Hoffmann, 116)

\section{Addressing by Personal Names}

The conventions of names as addresses differ in different societies: According to Scollon \& Scollon, in China (and in many other parts of Asia) there are different names for the family and for foreigners and they are not supposed to mix - it is asserted that a Chinese man is likely to feel great awkwardness if addressed by a foreigner by his Chinese name (meant for his family and friends) rather than his assumed European name (e.g. David) chosen for the situation of intercultural communication (2001: 134-137).

The choice between first name and surname depends on the context and the culture - some cultures favour solidarity, others - deference. Furthermore, symmetry or disparity may be differently arranged. In other words, the choice between symmetrical solidarity (informality first names and absence of titles both for the speaker and for the addressee) vs. formality and symmetrical deference (the use of titles and surnames) is culture-specific and is governed by the concept of preferred distance. While in most countries in the West symmetrical solidarity seems to be the rule, in China and some other Asian countries, as noted by Scollon (2001) symmetrical deference is the accepted etiquette.

Taking one's own culture's etiquette and understanding of the appropriate distance for granted may result in a comical situation: as reported by Russian TV, during a meeting between the former American State Secretary Condoleeza Rice and the then Russian Foreign Minister Sergei Ivanov (Note 3) the clash of speech etiquettes led to a funny exchange when the latter called the former Madam State Secretary (Russians prefer deference and a greater social distance during public events); while the former called the Russian Foreign Minister Sergei (American culture is that of informality).

\section{Names as Attitude and Affect}

A disparity in addresses may indicate anger or disappointment, i.e. a change in attitude. See, for example, this talk with a former lover:

(8) - "Looking for someone, Mr Morris?" - "Byron to you, my love." 
- "Mrs Elias to you, Mr Morris." The licensee is emphatic. Byron has been Byron to her once, long ago. She heard the golden voice and went to his room that same night... Later, she returned to sleep in her own bed with the awakened ghost of the late Mr Elias. Byron has widowed her familiarity. She will endure him as a customer once a year, but that, Mr Morris, is all. (Miles, 1977: 177)

As the distancing expressed by the use of her surname preceded by the formal Mrs suggests, in Mrs Elias's opinion the relationship is over. In the words of the author, Byron was down-graded to Mr. Morris. (Ibid: 183)

The following example in a well-known Monty Python sketch, where the interviewer first drops Sir and then proceeds to try out increasingly informal addresses, shows the sociolinguistic appropriateness or inappropriateness of familiarity and the ludicrousness and inappropriateness of pushing intimacy boundaries without reciprocity:

(9) "Can I call you Edward?"

- "Yes, sure".

(Later) - "Can I call you Ted? “

..."OK."

“Well, Eddie baby." - "Excuse me, I do not agree to being called Eddie baby."

The interviewee refuses to accept this new closeness, just as he refuses to be addressed as pussycat, sugar plum, angel drawers. Being called Frank seems downright mockery.

As Pavlenko (2006) has shown, languages with diminutives (Italian, Russian, Polish) are very differently perceived by bilinguals compared to languages, such as English, where diminutives are mostly linguistically impossible. It should be emphasized that in Russian, Polish and Italian personal names have a variety of linguistic forms which form a regular paradigm with the suffixes expressing affect. Thus, the use of different versions of my own name in Russian - Ira, Irochka, Irka, serves as a contextual cue to signal such attitudes as praise, disapproval, familiarity, and a range of other sentiments linguistically impossible in English. A full name, on the other hand, for example Irina, is likely to be used in a formal situation, or as a prelude to an implied criticism:

(10) Why haven't you tidied up your room, Irina, - you know you don't have any servants!

In English, on the other hand, clipped forms may cause some kind of confusion because it is not always clear whether the speaker means the same person, or a different one:

(11) "My name is Tom”. "Tom?” She sounded amazed.

.... Manuel ...had called me Thomas, a minor variation but an important one. Rebecca, at some level doubted my identity. ... "Or Thomas." "Which do you prefer?" "Either. It doesn't matter. Pick one," I said. Things were getting interesting. What I mean to say is that I am not uninterested... in the business of 
naming, particularly nicknaming, which I regard as socially acceptable, antisocial humiliation. (Antrim, 2000: 82)

Different clipped versions of the same name may serve to differentiate between different "Thomases" and in this way restrict the class of persons designated by this name; alternatively, they may be used in different contexts by different people suggesting a certain attitude to the bearer of the name.

This regularity of usage in specific contexts and the word-building suffixes or other forms used seem to suggest that diminutives and clipped versions of the personal names should be treated as linguistic forms or versions of the same name, rather than sobriquets.

\section{Names and Status}

The reciprocity in the use of first names signifies equal status, even though such equality may be context-specific and a function of the space - private or public. Thus, a subordinate and a boss may use first names reciprocally in private but not in the boardroom. Conversely, an absence of symmetry in addresses (e.g. first name vs. surname), which is often due to status and power relationship, results in vertical disparity:

(12) Could you write up a one-page summary for tomorrow's board meeting, Bill?

Of course, Mr Hutchins.

The example above is an ordinary business dialogue in a British company and quite easy to interpret: Bill is likely to be the subordinate and Mr. Hutchins - the boss. (Scollon, 2001:26) Hence the up and down roles evidenced by an informal address vs. a formal address are accounted for by the respective positions in the company and are the reason why the dialogue is characterized by vertical disparity (Ibid).

Mostly, people are acutely aware of this manipulation of inequality through disparate addresses, as in (13 a-b) where the equalizing function of first names, the peer role and the resulting closeness becomes salient:

(13) a. "Why were you following me, Alfred?"

Spinx stopped and stared with nervous resolution at Dalziel.

"Excuse me, $M r$...er...?"

“Dalziel, Superintendent.”

"Superintendent, I'd rather you didn't use my Christian name. I've studied a bit of criminology and I know it helps to establish a proper subordinate and familiar relationship with a suspect, but you know who I am now and I'd prefer to talk at the level of equals.'(Hill, 1993: 109)

b) "Do you really believe this, Sherwin?"

It was Leslie Constant again, daring to speak Lang's Christian' name and in this way, assume a peer role and mildly undermine her supervisor's guru status 
- a potentially dangerous tactic with this man. (Antrim, 2000: 41)

Depending on the culture, age may or may not be a barrier to a symmetrical use of first names. Noreen Dresser describes a meeting between an elderly Hindu woman and a young American. The young American who seemingly got on very well with the older Hindu woman asked the elderly woman, Mrs Rao, what her name was. The answer was - "Mrs Rao". The young American's feelings were hurt while to the elderly Indian woman the question seemed very rude because of the age difference and the implied respect of one's seniors: in India age is a barrier for the use of first names. (Dresser, 1996: 186)

Distorting the roles in addresses creates a powerful impact: in the film The Devil Wears Prada, when Miranda's husband decides to divorce her, she says that all newspaper splashes on page 6 will be about the end of another $M r$. Priestly thus alleging the derivative importance of all her husbands for society. Fiction reflects real life: when Carlo Ponti, the famous Italian producer of Doctor Zhivago fame, died the question often discussed was: Was he really $\mathrm{Mr}$ Loren?

\section{Sobriquets}

In my view, nicknames or sobriquets are metaphorical or coded linguistic forms (Note 4). They are often generated as descriptive epithets or metonyms and in general, they form part of the universal metaphoric networks in the sense of Lakoff (1980).

In many ways sobriquets are a function of the shared cultural knowledge, of the common cultural discourse. They are inter-textual by definition: being in most cases encoded secondary signs, they may be understandable only to those who know the primary sign or the referent, i.e. they may be clear to the in-group and obscure to the outsiders. The shared knowledge I have referred to above may or may not be culture-specific, chronologically variable or context-based. Thus in England in the 60-ies somebody called Elsa was automatically referred to as Lioness:

(13) ... a girl whose name was Elsa and whom naturally we called Lioness - used to tell me .... . (Vine, 1988: 31)

Lioness was metonymically modelled after Elsa, the lioness, raised in Kenya by George and Joy Adamson, who was very much a media star at that time.

The following extracts (14a-b) suggest a very obscure code, and as it becomes apparent from the context, the nicknames below are culture-specific and unlikely to be deciphered by outsiders.

(14) a. "Where's Mrs Thing?"Briggs demanded. This was the woman Sir Peveril paid to come and look after the flat. .... The other residents always called her Mrs. Thing. At first I thought that was her name and once called her by it, just after we moved in, causing much offence. How was I to know that was the British generic name for those who do such work. Even the communists, which we were, used it. (Bailey, 1999:14) 
b. "'Bruno - it is Bruno, isn't it? Excuse, darling. Someone told me about you and Briggs. ... Where's Loomie?"

She meant Adrian Pym, of course. Oh, those upper-class nicknames, those Biggins, Coccos, Dumphies, Heffers, Tatas and Simsims - but at least her use of the soubriquet made it less likely that she was a full-blown German spy. (Ibid)

Nicknames may be based on a chance association and create a secret personality for the user. In The Keys to the Street by Ruth Rendell the heroine, Mary, calls the dosser (street man) she is interested in Nikolai after she has seen him reading Nikolai Gogol's Dead Souls and in her mind the sobriquet gives him a singular coded identity known only to her.

Another interesting example of signifying through a name is provided in The Devil Wears Prada, where Miranda Priestly, played by Merrill Streep, calls all her assistants Emily. The name which is thus turned into a sobriquet becomes for her a means of equating a job to a person. Her new assistant Andrea becomes, for example, "my new Emily." But when she finally accepts and gets to respect her new employee she starts calling her by her real name, Andy.

\section{Names and Change}

Not surprisingly, the associations conjured up by names change with generations:

(15) "One of his sons is dead. The other one, his name was Kenneth, was born in February nineteen twenty-one."

“All these Kens," she said.

"As you say. It must have been the sexy name. These days Kens are all Chinese cooks.” (Vine, 1998:166)

It is obvious that not only do naming conventions change with time, but so does the incidence of the use of different categories of names as addresses. For example, in the $19^{\text {th }}$ and early $20^{\text {th }}$ century in the Russian naming system names followed by patronymics, such as Ivan Petrovich, Galina Sergeevna, used to be quite common and typical addresses both in the private space, i.e. among close friends, and the public space. Currently, however, patronymics are in decay in private space, although they are still prominent in public space. In many countries, including Great Britain, the use of first names is now much more prominent and independent of the distance than fifty or one hundred years ago. The examples (16a-c) provide some interesting illustrations:

(16) a. Today, in similar circumstances, I think we girls would have called his mother by her first name, but then (the novel is set in early 1960-ies - IP) she was Aunt Lois to Elsa and Lady Thinness to me. (Vine, 988: 45)

b. If you insist on calling me by my Christian name, you should at least call me 'Aunt Constance. Otherwise you make me sound like an upstairs maid. (Gosfard Park) 
c. ' 'My name is Rudolf,' he says 'What is your name?' Imagine addressing a man by his forename on the first meeting! Imagine him addressing you by yours! So she tells him all her names." (Treitel, 1992:102)

It should be noted that 16a. is set in early 1960-ies whereas the action in 16b., Robert Altman's Gosfard Park, unfolds in the 1930-ies and the period comment is made by a member of aristocracy, Lady Trentham, played by Vanessa Red grave. The story referred to in $16 \mathrm{c}$. takes place in the 19 th century.

In general it would seem that the drift of these global changes in addressing is dictated by equality and the new communicative code is characterized by greater informality.

\section{Conclusion}

Personal names are multi-dimensional. On the one hand, their intertextuality makes them a determinant of social and political identity and an instrument of control, submission and otherisation, and on the other hand, they should be viewed as markers of memory, attitude and affect. The conceptual characteristics of proper names may be implicated and based on interpretative resemblance.

Naming conventions as well as the incidence of the use of different categories of names as addresses differ spatially and temporally. The use of names as addresses is a function of status, and a disparity in this use would suggest inequality. Conversely, reciprocity in the use of first names signifies equal status, even though it may be context-specific. In some languages the use of different forms of the same name may serve as a contextualization cue indicating a change of attitude.

As secondary signs, sobriquets are a function of the shared cultural knowledge and a means of signifying. Quite often, they are obscure to an out-group.

The socio-cultural associations conjured up by personal names change with every generation, and in this way personal names become part of a new communicative code.

\section{References}

Aisoli-Orake, R. (2002). Communicative Styles of In-Laws in the Kara Society of Papua New Guinea. Smaller Languages in the Big World. Sociolinguistics and ELT.

Antrim, D. (2000). The Verificationist. Bloomsbury Publishing.

Apostolova, G. (2006). Bad Realism and Good Fantasy in Futile Attempt at Literary. Representation in Julian Barnes' "The Porcupine" and J. K. Rowling's "Harry Potter". ESSE -8, London.

Austin, J. L. (1962). How to do things with words. Oxford: Clarendon Press.

Bailey, H. (1999). After the Cabaret. London: Warner books.

Chagnon, N. (1992). The Yanomamo. New York: Harcourt, Brace, Jovanovich

Christie, A. (1984). They Came to Baghdad. NY: Berkley. 
Dorney, P. (2004). Chinese Take away. Singapore: Pennine.

Dresser, N. (1996). Multicultural manners: essential rules of etiquette for the $21^{\text {st }}$ century. John Wiley and Sons.

Furst, A. (1998). Night Soldiers. London: HarperCollins.

Giddens, A. (1991). Modernity and Self-Identity: Self and Society in the Late Modern Age. Cambridge: Polity.

Hoffman, E. (1989). Lost in Translation. New York: E.P. Dutton.

Lakoff, G., \& Johnson, M. (1980). Metaphors we live by. University of Chicago Press.

LDELC. (2005). Longman Dictionary of English Language and Culture. Pearson Education Limited.

Georgieva, M. (Ed.). Sofia: British Council Bulgaria and Lettera.

Miles, K. (1977). Sea Voices. The Times Anthology of Ghost Stories, London: Corgi.

Morgan, J., O’Neill, Ch., \& Harre, R. (1979). Nicknames: Their Origins and Social Consequences. Routledge \& Kegan Paul.

O’Brien, F. (1967). The Third Policeman. MacGibbon \& Kee Ltd.

OCEL. (1992). The Oxford Companion to the English Language. Oxford: Oxford University Press.

Pavlenko, A. (Ed.). (2006). Bilingual Minds: Emotional Experience, Expression and Representation. Clevedon, GBR: Multilingual Matters Limited.

Perianova, I. (2002). Discourse and the Language of Avoidance. Foreign Language Teaching (in Bulgarian, No. 4, pp. 51-66).

Rendell, R. (1994). The Crocodile Bird. Arrow Books.

Rendell, R. (1997). The Keys to the Street. Penguins.

Rhys, J. (1982). Wide Sargasso Sea. New York: Norton.

Scollon, R., \& Scollon, S.W. (2001). Intercultural Communication. Blackwell.

Sperber, D., \&Wilson, D. (1986). Relevance: Communication and Cognition, Blackwell.

Treitel, J. (1992). Waltz Time. In G.Gordon, \& David Hughes (Ed.), Best English Short Stories (Vol. IV). Norton.

Vine, B. (1988). The House of Stairs. Viking.

Vine, B. (1998). The Chimney Sweeper's Boy. Viking. 


\section{Macrothink}

Issues in Social Science

ISSN 2329-521X

2015, Vol. 3, No. 1

Notes

Note 1. It should be emphasized that I do not make any pronouncements on the artistic merits of the works referred to.

Note 2. Note the metaphoric use of the proper name Don Juan to designate a person who stands for oblivion rather than memory

Note 3. Russian TV 1st channel (ORT) news - 15th October 2005

Note 4. Unlike Morgan, (Morgan et. al, 1979) I do not categorize diminutives as sobriquets because in my view they are not metaphorical but represent a kind of paradigm characterizing social and psychological distance and context. 